
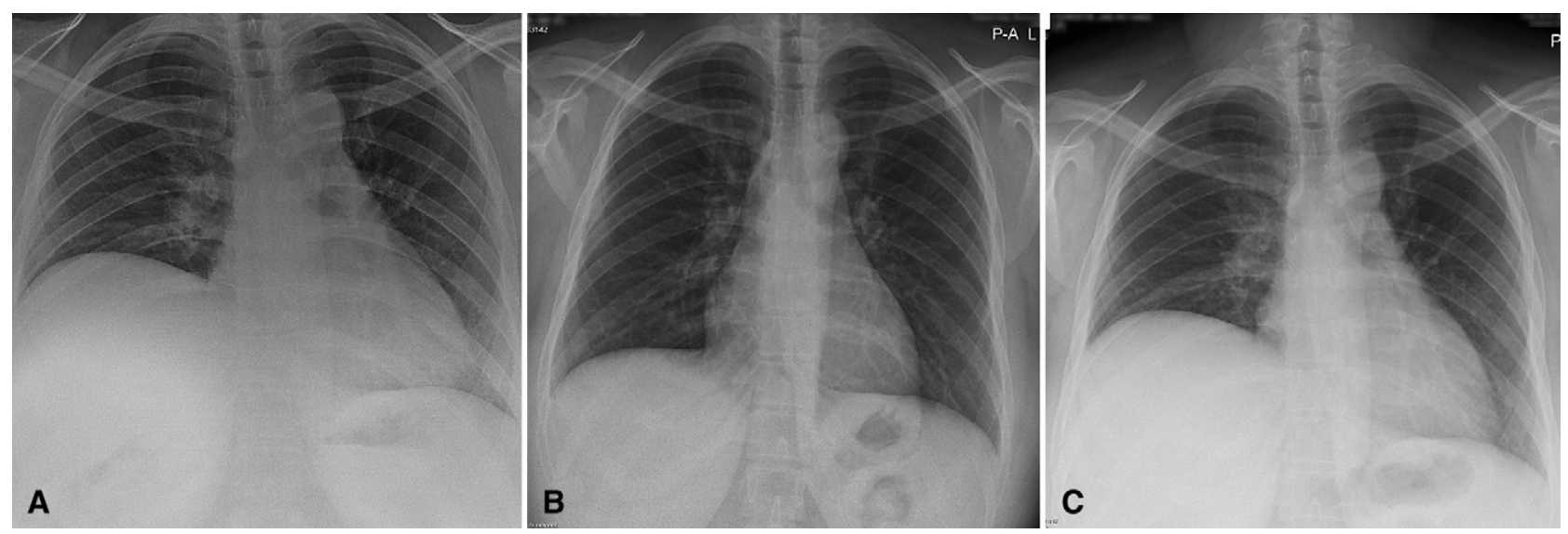

FIGURE 1. Intermittent raised hemidiaphragm at time of finding (A), improved at time of initial preoperative assessment and 18 months later (B), and raised again at 32 months $(\mathrm{C})$.

hemidiaphragm raise at one stage occurred some months after cessation of that drug. Likewise, the timing and brevity of exposure to clofazimine makes it an unlikely culprit.

We postulate that in this case of MRS intermittent diaphragmatic paralysis of unknown etiology may have been an unusual extracranial neuropathy. We suggest that the diagnosis be considered in other patients with peripheral neuropathies in the context of granulomatous cheilitis.

\section{References}

1. Ang KL, Jones NS. Melkersson-Rosenthal syndrome. J Laryngol Otol. 2002;116: 386-8.

2. Sbano P, Rubegni P, Risulo M, De Nisi MC, Fimiani M. A case of idiopathic granulomatous cheilitis and vulvitis. Int J Dermatol. 2007;46:720-1.

3. Aluclu MU, Keklikci U, Guzel A, Unlu K, Tatli M. Melkersson-Rosenthal syndrome with partial oculomotor nerve palsy. Ann Saudi Med. 2008;28:135-7.

4. Chan YC, Lee YS, Wong ST, Lam SP, Ong BK, Wilder-Smith E. MelkerrsonRosenthal syndrome with cardiac involvement. J Clin Neurosci. 2004;11: 309-11.

\title{
Staged repair of pectus excavatum during an aortic valve-sparing operation
}

\author{
Natacha Rousse, ${ }^{\mathrm{a}, \mathrm{b}}$ Francis Juthier, MD, PhD, ${ }^{\mathrm{b}}$ Alain Prat, MD, ${ }^{\mathrm{b}}$ and Alain Wurtz, MD, ${ }^{\mathrm{a}}$ Lille, France
}

Controversy remains regarding the concomitant repair of pectus excavatum and an aortic root aneurysm in patients with Marfan syndrome. The pectus deformity may impair optimal operative exposure of the aortic root, whereas cardiopulmonary bypass coagulopathy would increase bleeding after pectus excavatum repair. The concomitant

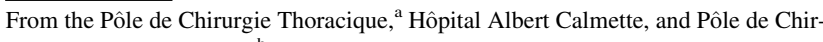
urgie Cardiovasculaire, ${ }^{\mathrm{b}}$ Hôpital Cardiologique, CHU de Lille, Lille, France. Disclosures: Authors have nothing to disclose with regard to commercial support. Received for publication Oct 7, 2010; revisions received Dec 17, 2010; accepted for publication Jan 10, 2011; available ahead of print March 14, 2011

Address for reprints: Alain Wurtz, MD, Pôle de Chirurgie Thoracique, Hôpital Albert Calmette, CHU de Lille, F59037, Lille Cedex, France (E-mail: alain.wurtz@ chru-lille.fr).

J Thorac Cardiovasc Surg 2011;141:e28-30

$0022-5223 / \$ 36.00$

Copyright (C) 2011 by The American Association for Thoracic Surgery doi:10.1016/j.jtcvs.2011.01.019
}

surgery requires (1) a minimal bleeding period during pectus correction, (2) optimal operative exposure during aneurysm repair, (3) efficient chest-wall stabilization using a device that allows urgent postoperative reentry or cardiopulmonary resuscitation maneuvers if needed, and (4) a satisfactory cosmetic result.

Our technique is a modified Ravitch procedure, with staged resection of the cartilages before and after aortic root aneurysm repair. The procedure starts with a midline presternal incision. The pectoralis muscles are reflected superiorly, and the rectus abdominis is detached inferiorly. The lower cartilages (fourth to sixth and extremities of the seventh) are subperichondrially resected, whereas the xyphoid process is preserved (Figure 1, A). After a median sternotomy, aneurysm repair is then performed under cardiopulmonary bypass. Last, after sternum closure, pectus repair is achieved by performing additional resection of 


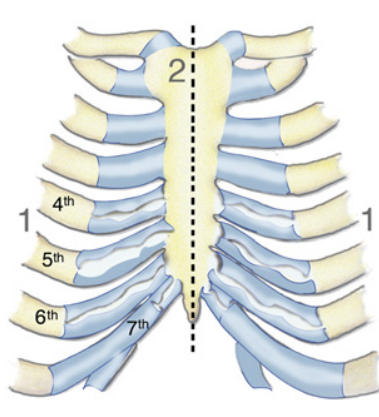

A

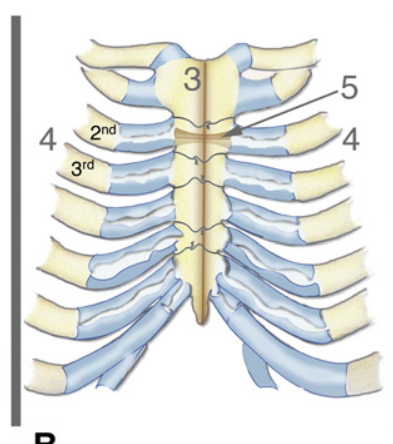

B

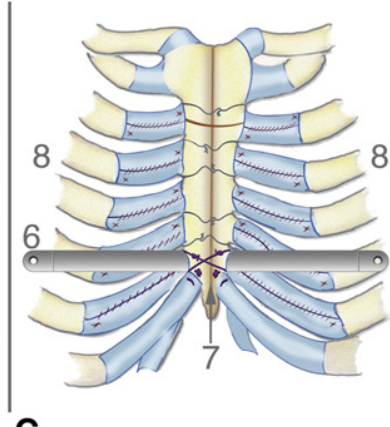

C

FIGURE 1. A, (1) Subperichondrial resection of the lower cartilages (fourth to sixth and extremities of the seventh) and (2) sternal split (dotted line) allowing the aortic root aneurysm repair. B, (3) Sternum closure, (4) additional resection of the upper second and third cartilages, and (5) wedge sternal osteotomy at the manubriosternal junction. C, (6) Retrosternal metallic strut placed anterior to the ribs laterally and secured to the sternum, (7) stitching of the seventh cartilages to the base of sternum, and (8) "ruffling" sutures of the perichondrial sheaths, giving a shortening effect.

the upper second and third cartilages and a wedge sternal osteotomy at the manubriosternal junction (Figure 1, B). Sternum stabilization is ensured using an easily removable

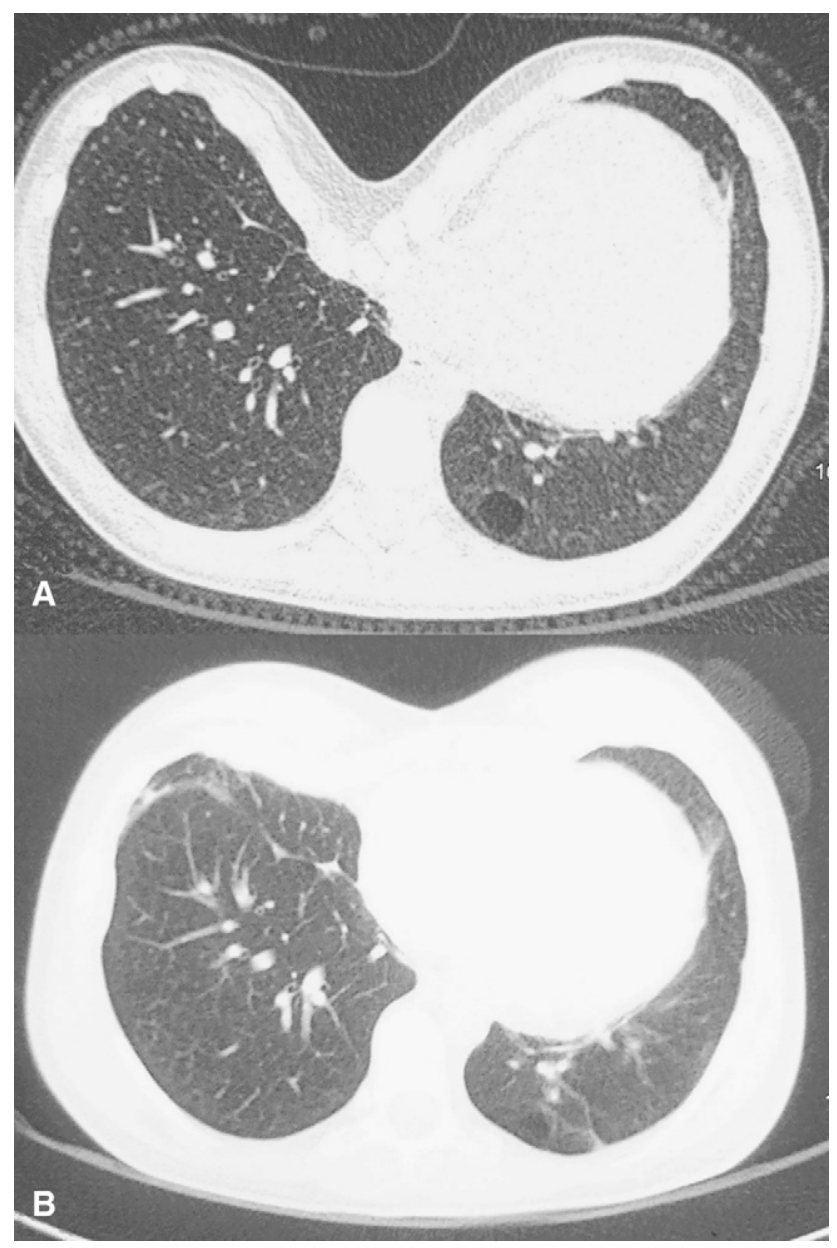

FIGURE 2. Preoperative and postoperative computed tomography chest scans in patient 1 showing (A) the severity of the asymmetric pectus deformity (pectus index, 7.10) and (B) the satisfactory correction of the anterior chest wall (pectus index, 2.6). retrosternal metallic strut (Medicalex, Bagneux, France) placed at the level of the sixth perichondrial sheaths, anterior to the ribs laterally, and secured to the sternum with an absorbable suture. The seventh cartilages are stitched to the base of sternum, followed by a "ruffling" suture of the perichondrial sheaths (Figure 1,C). The pectoralis muscles and rectus abdominis are reapproximated, and the subcutaneous layers and skin are closed over 2 suction drains. Strut removal is performed under local anesthesia through a 1-cm-long lateral skin incision on an outpatient basis 6 to 8 months after the initial procedure.

\section{CLINICAL SUMMARY}

The modified Ravitch procedure was performed in a 14year-old girl and a 37-year-old man who had Marfan syndrome, aortic root aneurysm, and severe asymmetric pectus excavatum (pectus index: 7.10 and 5.94, respectively) (Figures 2, A, and 3, A). Both patients underwent an aortic valve-sparing operation according to the David inclusion technique with a Vascutek Gelweave Valsalva graft (Terumo Cardiovascular Systems Inc, Ann Arbor, Mich), extended to an aortic-arch replacement, with cerebroplegia and circulatory arrest in the second patient. On postoperative day 1, overall blood loss was 490 and $450 \mathrm{~mL}$, respectively. The chest tubes and suction drains were removed on days 4 and 5 , respectively. The female patient was extubated on day 1 and discharged on day 10 . The male patient required prolonged mechanical ventilation for 16 days because of an ischemic stroke. He was discharged on day 44 with minimal neurologic sequelae. The metallic strut was removed at 8 and 7 months, respectively. Long-term follow-up showed excellent cosmetic and radiologic results (pectus index: 2.6 and 2.06, respectively) (Figure 2, B).

\section{DISCUSSION}

The concomitant repair of pectus excavatum and aortic root surgery in patients with Marfan syndrome is 


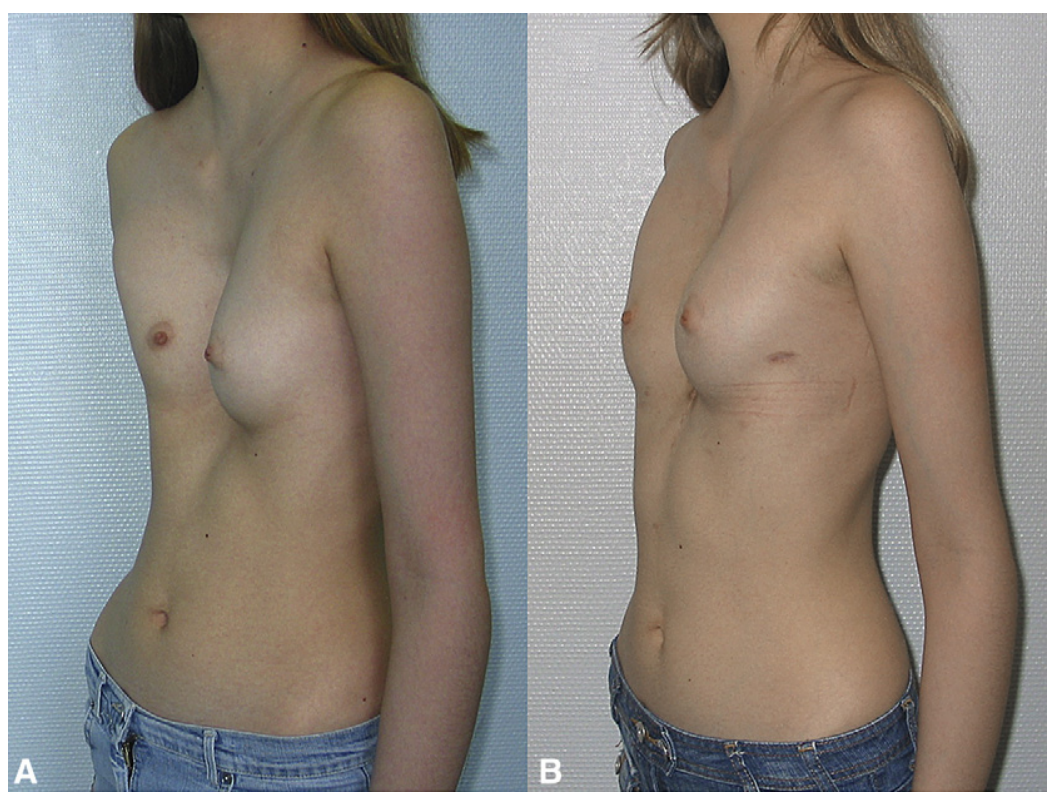

FIGURE 3. Preoperative (A) and 6-month follow-up postoperative (B) photographs in patient 1 showing the pectus deformity with severe thoracic distortion and the near normal symmetry after pectus repair.

challenging, and controversy remains with regard to pectus excavatum repair and chest-opening techniques. Ravitchtype procedures, followed by a sternal split or parasternal approach, ${ }^{1}$ have occasionally been used. More invasive operations have also been described, such as the sternal turnover, ${ }^{2}$ eversion in a trapdoor fashion, or turnover with internal thoracic-vessel preservation. ${ }^{3}$ These techniques offer excellent operative exposure but are associated with a high risk of wound infection or sternal necrosis, despite preserving the internal thoracic blood supply. ${ }^{3}$ Ryu and colleagues ${ }^{4}$ performed aortic root and mitral valve surgery through a trapdoor exposure, ${ }^{3}$ followed by pectus excavatum repair using Nuss bars placed across the mediastinum under the pedicled sternum. Despite a cosmetically appealing restoration of the chest wall, the authors were aware that this approach might present difficulties for urgent postoperative reentry. Furthermore, the presence of Nuss bars impairs the effectiveness of chest compression if cardiopulmonary resuscitation ${ }^{5}$ is required.

\section{CONCLUSIONS}

Our staged Ravitch-type procedure has several advantages. Despite full anticoagulation, bleeding is minimal with careful preservation of the perichondrium, which protects the intercostal and internal thoracic vessels from damage. Resecting the lower cartilages before sternotomy leads to sternum elevation, facilitating chest opening. Sternal-retractor stability with optimal operative exposure is achieved during aortic root aneurysm repair because of the provisional preservation of the upper cartilages. Preservation of the internal thoracic arteries ensures appropriate sternal healing. In our technique, the use of an easily removable sternal support inserted at the lower edge of the sternum does not impede a possible reentry or a potential cardiopulmonary resuscitation, in contrast with the Nuss bar. ${ }^{4,5}$ The procedure offers excellent long-term cosmetic results.

The authors thank A. Vincentelli for editorial assistance and E. Rousse for the artwork.

\section{References}

1. Javangula KC, Batchelor TJP, Jaber O, Watterson KG, Papagiannopoulos K. Combined severe pectus excavatum correction and aortic root replacement in Marfan's syndrome. Ann Thorac Surg. 2006;81:1913-5.

2. Wada J, Ishida T, Hasegawa T. Results of 271 funnel chest operations. Ann Thorac Surg. 1970;10:526-32.

3. Doty DB, Hawkins JA. A turnover operation for pectus excavatum at the time of correction of intracardiac defects. J Thorac Cardiovasc Surg. 1983;86: 787-90.

4. Ryu YG, Baek M-J, Kim HK, Choi YH, Sohn Y-S, Kim HJ. Simultaneous repair for aortic incompetence with annuloaortic ectasia and pectus excavatum by modified Ravitch procedure with pectus bars in an adult patient with Marfan syndrome. J Thorac Cardiovasc Surg. 2009;137:e34-6.

5. Zoeller GK, Zallen GS, Glick PL. Cardiopulmonary resuscitation in patients with a Nuss bar-a case report and review of the literature. J Pediatr Surg. 2005;40: $1788-91$. 